\title{
Proceedings of the Bovine Respiratory Disease Symposium 2014: New Approaches to Bovine Respiratory Disease Prevention, Management, and Diagnosis
}

\author{
Received 6 October 2014; Accepted 14 October 2014
}

This issue of Animal Health Research Reviews contains the Proceedings of the Bovine Respiratory Disease Symposium 2014: 'New Approaches to Bovine Respiratory Disease Prevention, Management and Diagnosis', which was held on July 30 and 31, 2014 in Denver, Colorado, USA. Bovine respiratory disease (BRD) remains a leading cause of illness, death and decreased productivity for cattle in North America and around the world. The 2014 BRD Symposium provided a forum for specialists from a variety of fields to present novel information that has surfaced since the 2009 BRD Symposium. Topics addressed included BRD diagnosis, with much discussion of the challenge of accurate diagnosis in the field; the influence of genetics in BRD, new developments related to microbial pathogenesis, and the evaluation and control of BRD in populations. The meeting brought together scientists, educators and students, veterinarians, and policy makers to consider how the latest BRD research findings and emerging management technologies can be translated into field practices to improve the health of cattle. Participants attended lectures and engaged in lively discussions with the speakers. A special panel consisting of veterinarians working in beef and dairy practices spoke about their observations regarding BRD impact and diagnosis. A poster session featuring current and ongoing research related to BRD was also held, with awards given to outstanding student presenters.
The Symposium was organized through the efforts of members of the United States Department of Agriculture (USDA) Multistate Research Project NC-1192, 'An Integrated Approach to the Control of Bovine Respiratory Disease', and participants in the USDA National Institute of Food and Agriculture Agricultural and Food Research Initiative (NIFA AFRI) Bovine Respiratory Disease Complex Coordinated Agricultural Project (BRD-CAP). Special thanks go to the Academy of Veterinary Consultants (AVC), the American Association of Bovine Practitioners (AABP), and numerous industry sponsors for their partnership in presenting the 2014 BRD Symposium. Many thanks also go to Linda Hoffner and Paula Lehman, who were instrumental in the organization of the meeting. It is hoped that the information presented at the 2014 BRD Symposium will foster the application of new ideas and the development of new collaborations to the improvement of bovine health.

Amy E. Young ${ }^{1}$ and Amelia R. Woolums, ${ }^{2 *}$

${ }^{1}$ Department of Animal Science, College of Agricultural and Environmental Sciences, University of California, Davis, Davis, CA 95616, USA

${ }^{2}$ Department of Large Animal Medicine, College of Veterinary Medicine, University of Georgia, Athens, GA 30602, USA

*Corresponding author. E-mail: awoolums@uga.edu 